\title{
IDENTIFICATION OF CHALLENGES AND OPPORTUNITIES OF THE TRANSPORT MASTER PLAN IMPLEMENTATION IN THE CITY OF KIGALI-RWANDA
}

\author{
DAVID NKURUNZIZA, RAHMAN TAFAHOMI \& IRUMVA AUGUSTIN FARAJA \\ College of Science and Technology, University of Rwanda, Rwanda
}

\begin{abstract}
The city of Kigali aspires to be a center of urban excellence in Africa. This has been demonstrated by its inclusiveness and openness toward reviewing the master plan to address actual challenges and opportunities presented by new developments. There have been two major editions of the Kigali Master Plan: one in 2013 and another in 2020. Transportation planning being a major subset of overall urban planning, this research intends to identify various challenges and opportunities presented by both revisions. This research has also explored road network planning issues. Both editions of the master plan coupled with the 2012 Strategic Transport Master Plan have been thoroughly reviewed. A factor of future proofing has driven the comparative analysis, considering major transitions that are taking place globally, including climate change and present-day shift towards sustainable transportation. The study has classified opportunities and challenges into five categories. Technical and economic challenges are most prominent. For instance, the lack of customized and standardized guidelines for traffic engineering and road design specific for Rwanda, and limited funding for infrastructure projects are key challenges. The social aspect presents an almost equal share of challenges and opportunities. Some key advantages include the abundance of local labour and popularity of public transport. The unwillingness to relocate in case of expropriation, and failure to consider daily living standards of citizens pose a major disadvantage, however. On the side, political and environmental aspects of implementing the master plan, presented relatively more opportunities than challenges. Fast and forward, the Government has set high standards of green transport policies that are interwoven by other policy aspects in urban planning. The topographic landscape of the City of Kigali presents a major multi-aspectual disadvantage, however.
\end{abstract}

Keywords: Kigali, transport master plan, road network, urban planning.

\section{INTRODUCTION}

The city of Kigali is the capital city of the Republic of Rwanda. As per the 2018 survey, the population of Kigali stood at 1.2 million and is expected to grow up to 5 million in the next 25 to 30 years [1]. Economic growth often follows intense growth in population, especially in developing countries [2]. Rwanda is expected to follow the same trend. The population of Kigali has steadily grown from 6,000 in 1960 to over 200,000 in the early 1990s. The population doubled to over 600,000 people in the year 2000 [3]. The urban migration continued and many people preferred settling in the capital, where there were more job opportunities. This has led to a spontaneous and uncontrolled growth which resulted into inefficient use of land and other resources [4].

Transportation is an integral part of growth for a city. Its state directly impacts the economic viability, performance, safety and liveability of a city [5]. The transportation master plan is developed to ensure that Kigali is well-equipped to fulfil the transport requirements of a modern city while supporting a healthy economic growth and promoting a higher quality of life. It can help in mitigating the effects of climate change and provide sustainable measures to adapt to the changes [6]. The transport sector is viewed as contributing considerably towards poverty reduction and economic growth, and serving as 
support to other economic sectors. It will continue to play a fundamental role in the economy of Rwanda [5].

According to Sun et al. [7], the transportation environment is a basic economic interaction between supply and demand. A mature transportation system displays this interaction best [8], [9]. The area where the biggest demand exists, like a densely populated urban area for instance, typically has a dense road network and public transport infrastructure to serve the demand for transportation that exists there [10]. In a developing environment though, like for the City of Kigali, the challenge is to use transportation interventions to have a catalytic effect to "create" a demand where, at present, it may not be to the extent that warrants the investment [9].

Urbanisation does not happen in a silo, as it is usually accompanied by intricate challenges, including but not limited to, incessant demand for affordable housing, transport networks, basic services and jobs [2]. Currently, several intersections of the city road and roads connected to it are congested due to lack of traffic capacity [11]. Future population growth and increase of vehicle ownership are projected to cause traffic congestion and it is argued that it could worsen than it is currently. The road network in Kigali has begun to show signs of age, and while the overall condition of the network is healthy, it is expected to deteriorate further in the next 30 years, if a good maintenance regime is not put in place [12].

\section{BACKGROUND}

\subsection{Strategic transport master plan (2012)}

The Rwanda Strategic Transportation Master Plan (RSTMP) was developed in 2012 to solve national level transport issues. It covers a proposal of the institutional structure of transport sector as well as the delivery of transport infrastructure and services [13]. The strategy takes a long-term view on the future transportation system and identifies programs and projects to secure the integrity of the system. The RSTMP deals with the "strategic" layer of the transport system. Important criteria that relate to Road Network in the document are shown in Fig. 1.

\subsection{Kigali transport master plan, 2013 edition}

This Master planning task had by objective to review the planning direction and strategies for the entire City of Kigali, while integrating all the past planning and development initiatives undertaken. It prepared the Conceptual Kigali Transportation Plan and Final Kigali Transport Master Plan [14]. This included the review and integration of existing plans, so as to make available a complete city-wide transportation master plan for the whole of Kigali. This edition also established a GIS database for the entire City [6].

The Transportation Master Plan (TMP) is intended to set out a strategic vision for the City of Kigali in its pursuit to become a City of Green Transport [13]. It anticipated to make sure that future transportation needs for the City such as integrated network of roads, rapid and non-motorised transit, and policies and guides can be planned and budgeted for as the City grows. This TMP set the planning horizon at 2040. By doing so, the TMP defined the City as it would look in 2040. The City's growth is organic and difficult to foresee. As such, implementation projects in the TMP were current for the years 2013-2020. 


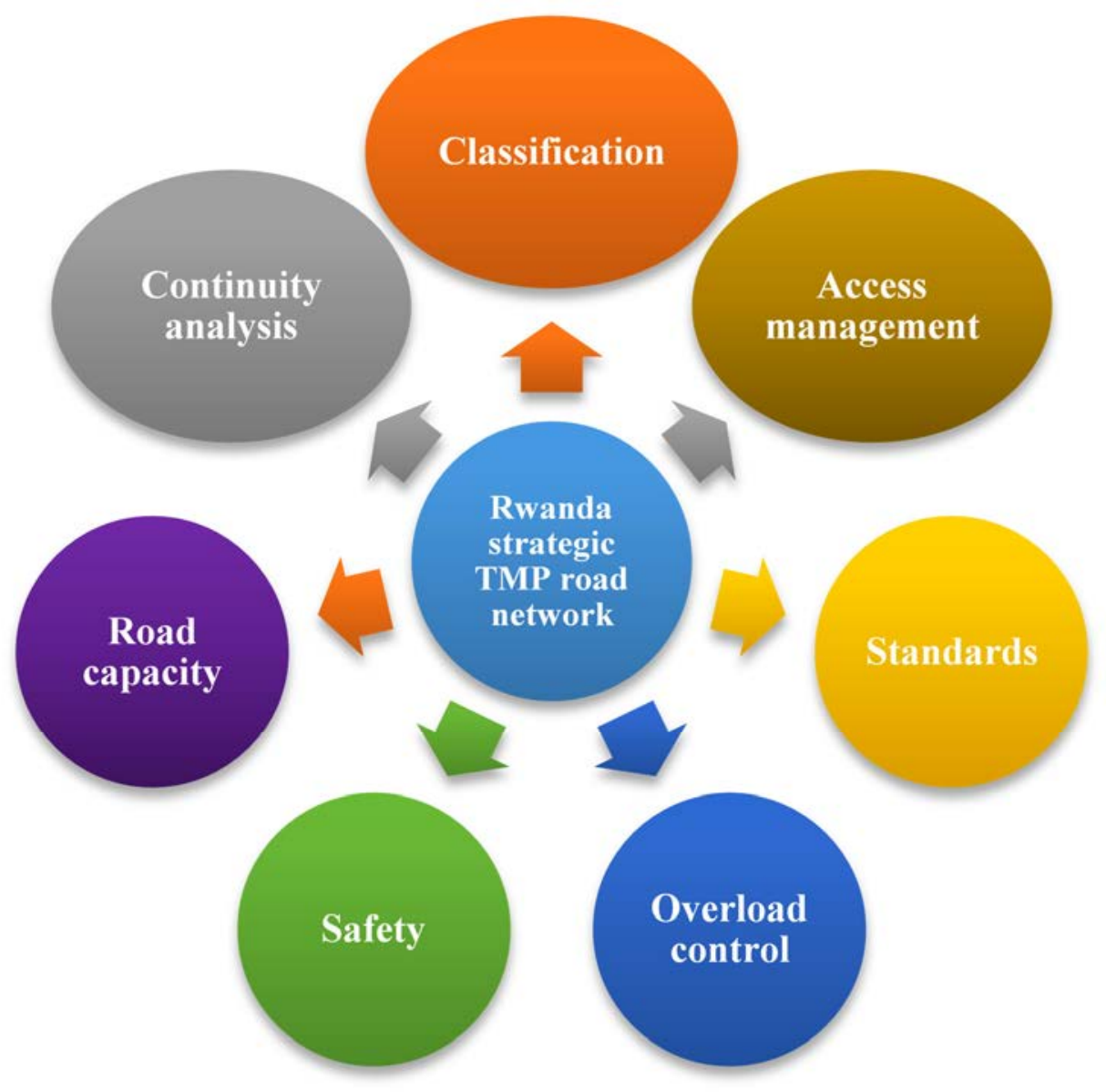

Figure 1: Important criteria that relate to the road network [13].

\subsection{Kigali transport master plan, 2020 edition}

In the beginning of 2018, the TMP was updated in conjunction with the Kigali Master Plan to ensure integration between planning, transport and infrastructure services. The transport sector is considered a strategic sector for Rwanda given that high transport costs are regarded as a hindrance to the economic growth and development of a country [4].

The 2013 Kigali TMP was updated with a new methodological approach based on two key elements:

1. An intense participatory process aimed at deeply involving a large base of stakeholders, capable of providing valued inputs and feedback during the process of updating [15].

2. Support this update with updated journey time survey data, traffic count survey data, and household travel survey data. This represented an opportunity to incorporate updated land use, road network databases and employment forecasts [15]. 


\subsection{Transport infrastructure composition in Rwanda}

Transport infrastructure is composed of various facilities that enable the mobility of people and goods, through different mediums, from one place to another [16]. In the case of Rwanda, the transport infrastructure is comprised of:

1. Passenger transport: This type of service is provided by both public and private sector. It includes bus, taxi and airline services.

2. Road Transport: This is the major medium of transport so far. The length of national paved roads increased from $1,279 \mathrm{~km}$ in 2015 to $1,355 \mathrm{~km}$ in 2016 [11].

3. Air Transport: There are two international airports (Kigali and Kamembe) and five other airports and airstrips spread across the country [4].

4. Lake Transport: This is less prominent and not used in the City of Kigali. It is only limited to Lake Kivu. Other fluvial forms of transport are limited to local boats due to more convenient alternatives.

5. Rail Transport: This type of transport is not yet in Rwanda. There are plans to build railways in Rwanda [4].

Since the adoption of the 2013 Transport Master Plan, many road infrastructure projects have been implemented in Kigali [3]. The road network has been improved, upgraded and rehabilitated in the past five years. The city topography, consisting of mainly valley and hills, remains as a natural restriction in the development of the road network.

According to the Fifth Integrated Household Living Conditions Survey (EICV 5) (2018), the percentage regular usage rates for all-weather roads for Kigali City decreased from $90.7 \%$ in $2013 / 14$ to $86.8 \%$ in $2016 / 17$. However, the number of residents living within 19 minutes' walk of the nearest all-weather road increased from $97.5 \%$ to $98.8 \%$. As per the percentage of people leaving different distances to all-weather roads in Kigali City in 2016/17, only $1 \%$ of Kigali City residents live more than $500 \mathrm{~m}$ from an all-weather road [3].

The 2013 Kigali TMP stated that only $14 \%$ of the $732 \mathrm{~km}$ road network in Kigali was paved [6]. The majority of roads in Rwanda are still unpaved. Major paved roads only occur in the urbanized areas of the City and most of the roads in the rural areas are in the form of mud tracks. New housing projects have come with the development of roads, sidewalks and other street infrastructure. According to the Statistical Year Book 2018 for Rwanda, there was an improvement, where $22 \%$ of roads in Rwanda were paved in 2016 [1].

\subsection{Study area}

The City of Kigali consists of three districts, namely: Nyarugenge, Gasabo and Kicukiro District [3]. The current and forecasted population densities are illustrated in Fig. 2. It can be concluded that the areas with the highest population density is in the centre of Kigali. The average population density is approximately 25 people per hectare. This expected to reach a maximum of about 53 people per hectare in 2050 [15].

\section{KEY CHALLENGES}

Although Kigali has implemented many measures to address urban mobility issues since the 2013 TMP, the steps required to ensure future mobility challenges are much bolder 


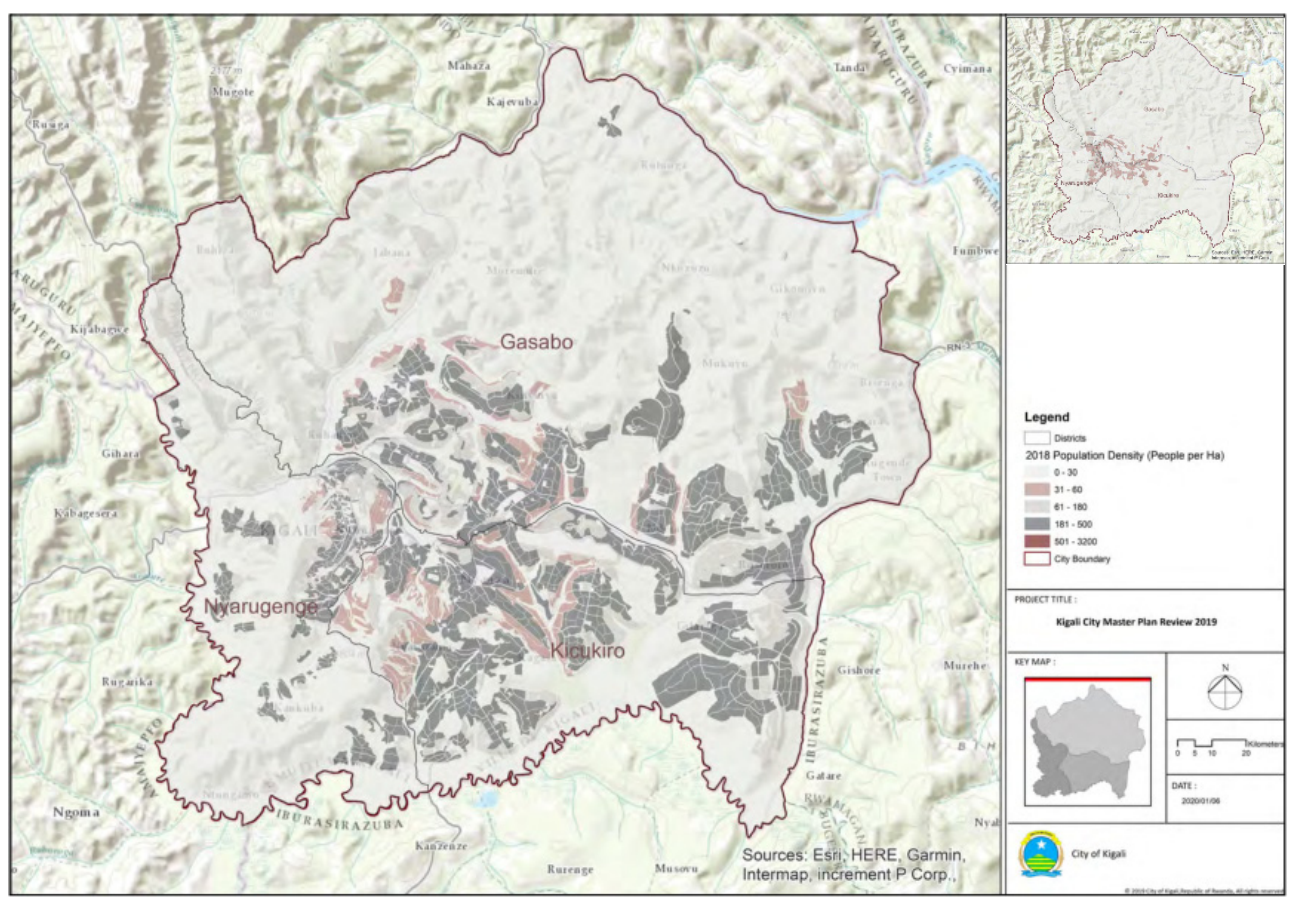

Figure 2: Population density (people per hectare) forecasted for 2050 versus the 2018 situation (upper-right) [15].

[17]. This study has identified 21 challenges. In this section, only eight are discussed for the sake of brevity. Some future mobility challenges that are expected to accelerate in the future include:

1. Rise of car ownership: While the number of vehicles in Kigali are still manageable at present, it is argued that in the planning horizons of 2040, congestion could occur and be expensive to rectify. The transport master plan needs therefore to actively promote the use of public transportation and non-motorized transportation as an alternative against the motorized mobility such as for cars.

2. Limited funding for infrastructure: The costs of building new transport infrastructure are already high. Looking at the inflation rate of $3.5 \%$ that closed the year of 2020 [15], It is argued that construction costs will continue increase as time goes by. In addition to this, maintenance cost of roads will be equally difficult as their length increases. While road maintenance funds are provided by the central government, the local authority will need to obtain additional funds, not only for building infrastructure and maintenance, but also for upgrading facilities like bus stops and bus stations.

3. Traffic engineering and design: As of the time of conducting this research, there was no local formal guideline - or standard - regarding geometric design of roads. While Rwanda forms part of the East African Community (EAC), it adopts right-hand drive. This implies that it is not possible to apply EAC design standards directly to Rwandan roads. In addition to this, various manufacturers of traffic signals have more than once proved to have produced cheap and poor traffic calming gadgets. Lastly, there is no 
known formal guideline that standardizes road markings and signs specific to Rwanda. Some have been adopted from old francophone Police signs.

4. Green transport network planning: Dedicated pedestrian and cycle routes are only provided in the city center. There is a lack for continuity in other words. Nonmotorized transport routes - such as for cycling - are disconnected. In addition to this, a hilly terrain which composes most of Kigali presents a challenge to the successful implementation of cycling.

5. Systematic development control: Upon further analysis of the TMP, it is clear that parking provision is not systematically enforced throughout Kigali. Moto-taxi parking is not included neither. This may cause potential disagreement between road users and landowners who may claim intrusion. On top of this, it does happen that buildings are approved in areas where spaces for transport systems have been set to expand. There should be a dedicated close analysis and solution to this problem.

6. Topography of Kigali: The road gradient for cycle paths should not be more than $5 \%$. In view of the hilly terrain of Kigali, it is a challenge to implement a comprehensive and continuous non-motorized network. The City is built on ridges and valleys and traversing these may be difficult for bicycles especially when it is not well integrated with the public transport.

7. Narrow roads in existing urban areas: There is no continuity in pedestrian facilities from one development to another, or commuter facilities. This will compromise on the safety of pedestrians. The existing urban areas are already very well built-up, and any upgrading or improvement work in the urban area could be very cost-intensive. There are also issues with land boundaries where land ownership can potentially prohibit future road expansion.

8. Lack of government land bank: The City of Kigali does not have sufficient land bank on which transportation infrastructure can be developed or where road widening can be done easily. The road network in the City has been developed extemporaneously. While the road network is well designed in new developments, the landownership is not always clear. This could result into legal problems.

These factors mean that without drastic measures, the mobility levels of service within the City are likely to continue deteriorate. Higher congestion and environmental pollution need to be avoided through the planning and implementation of larger scale public transport and non-motorised transport projects [9].

\section{KEY OPPORTUNITIES}

Among 16 identified opportunities, in both the 2013 and 2020 editions of the Kigali Transport Master Plan, here are eight key opportunities that stood out.

1. Economic growth: After the year of 2010, the growth rate of real Gross Domestic Product (GDP) has sustained a high ratio of around 7\% according to the Statistical Yearbook of 2016, from the National Institute of Statistics of Rwandan [18]. The availability of abundant local labour could enable the improvement of road infrastructure in urban areas and may also contribute to the reduction of poverty. There are also many economic opportunities in Kigali as Rwanda becomes relay station of trade between the Northern and the Central Corridor of East Africa [19].

2. Greenfield city: Much of Kigali area is underdeveloped or still Greenfield. As such, there is an opportunity for the City to develop or redevelop the transport network, especially in areas where road alignments are not suitable for major transit. A large 
proportion of rural areas in Kigali are low-income settlements. These informal settlements are not efficient in land use and are ripe for redevelopment [2].

3. Abundant local labor: This is among key solutions that are expected to drive the economy of Rwanda: Human Capital. For instance, the youth have been sensitized by the Government to be involved in remunerated jobs to fill the gap between the revenue generated in agriculture and the total expenditures of families. The construction sector is one of the largest providers of manual jobs outside of the agricultural sector [20].

4. High dependency of public transport: Currently the City of Kigali has a high modal share of public transport which stands at around $80 \%$ of the total travel of the city [21]. Due to Kigali's stage of economic and social development, the population is more receptive to the use of public transportation as a means of getting around the City.

5. Strong and good governance: Rwanda is one of the most progressive countries in Africa [9]. It has strong and good governance to implement the necessary infrastructure projects, including transportation projects to support the population and economic growth. The Government also encourages training at all levels, including language courses, and places technical training as a top priority. This will enable the country to acquire adequate human resources for the transport sector in the medium term at all levels.

6. Pro-sustainability government: The Government of Rwanda has acknowledged the importance of the Transport network and has commissioned several environmentalfriendly studies, such as public transport study in Kigali and a Transport Sector Strategic Plan. This shows willingness on behalf of the government to improve it.

7. Suitable climate: Kigali's moderate and relatively dry climate is suitable for pedestrians and cyclists and should be included in the planning of the transportation system [22]. While cycling is not readily adoptable in the City as the terrain is hilly, public transportation can be used to supplement any cycling networks or facilities.

8. Intercity transport system and sustainable transport network: Construct urban roads to a minimum density of $6 \mathrm{~km}$ per $\mathrm{km}^{2}$, generate seamless intermodal transport connectivity, construction of intercity freight route and infrastructures. All amenities and facilities served by public transport, establish green network and pedestrian friendly streets, implement transport policy effectively [15].

\section{ANALYSIS AND DISCUSSIONS}

\subsection{Categories and their interdepencies}

On top of discussed points, this study actually identified 21 unique challenges and 16 opportunities. This makes a total of 37 . The review was conducted on both editions of the master plan. These challenges came into various forms and shapes. The researchers made a qualitative analysis of each, and found that they tend to fall into five distinct categories:

1. Economic: These are challenges and opportunities related to access to finance, and economic implications they may present. For example, implementation of an expensive bus rapid route (BRT) is an economic challenge, while on the other side, presents social opportunities for overall public transport.

2. Social: These are points in the transportation master plan that tend to relate to the improving of life quality, for urban residents. For example, abundance of local labor is both an economic and social opportunity. In this case, there is an overlap. One opportunity may be shared by two or more categories. 
3. Environmental: These are most of the times geographical, topographical and climate related challenges. They may be direct or indirect results of human activities, or neither. For instance, hilly and mountainous is an environmental challenge. It is however not man-made. In the same time, it creates inconvenient non-motorized transport experiences, such as cycling and walking. Moreover, infrastructure costs in this kind of place, can be twice expensive, compared to that of a flat terrain. This is an economic challenge, therefore. Visibly, challenges can overlap from one category to another, and they are interdependent.

4. Political: These are opportunities or challenges that has to deal with policy, governance and leadership. Researchers classified the latter, stemming from the fact that a good policy has much power toward implementation of anything that can be planned. For obvious reasons, even the master plan stands as a policy in itself. So, much of what that has been found, has in one way or another, a relationship with political aspects of planning and implementing the TMP.

5. Technical: This is the last category of classification that contains opportunities and challenges relating to the technical feasibility of proposed solutions. In a way, Transportation is an engineering discipline, and requires a high level of technical capability. For instance, the fact that Rwanda has been chosen to be the headquarters of Smart Africa, offering a chance to first-hand experience some technology solutions in transport is an opportunity, while the lack of standardized road construction guidelines stood as a challenge on the implementation side. Therefore, all sides have been considered.

A survey was done, and each challenge and opportunity were weighed into varying influence which makes it to belong to either category. Weighing of categories has been done in the following manner (Table 1).

Table 1: Qualitative classification and corresponding scores.

\begin{tabular}{|l|c|c|c|}
\hline \multirow{2}{*}{ Type } & \multicolumn{3}{|c|}{ Relationship scale } \\
\cline { 2 - 4 } & Not related & Related & Very related \\
\hline Opportunity & 0 & 1 & 2 \\
\hline Challenge & 0 & 1 & 2 \\
\hline
\end{tabular}

It has been clear that some challenges overlap into various categories. Some technical challenges will present economic challenges, and so on. The analysis has been done using advanced data presentation techniques. It is important to mention that all items have been captured in both revisions of the Master Plan, including 2013 and 2020. Figs 3 and 4 show what the study found.

The study shows that technical challenges are more prominent with a share of $26 \%$. Lack of qualified local urban planners is supposedly the cause. It is argued that outsourced inputs are delivered outside the local context [23]. In addition to this, there is a lack of standard guidelines of road geometric design, traffic control instruments, and road markings that are specific to Rwanda [22]. This technical challenge has a close relationship with the education system in Rwanda and its history. As an emerging economy, there were few resources and opportunities to developing a workforce that could be accountable to what is happening right now. The Master plan, should have been designed when the city was formed [13]. The current government administration has heavily invested in education, 


\section{Challenges}

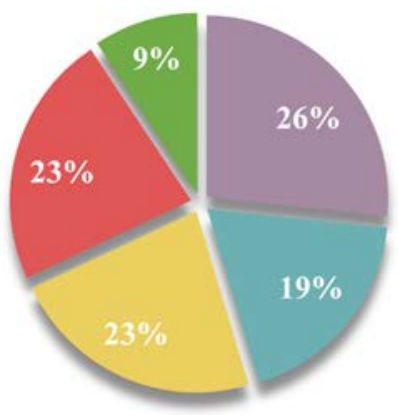

Opportunities

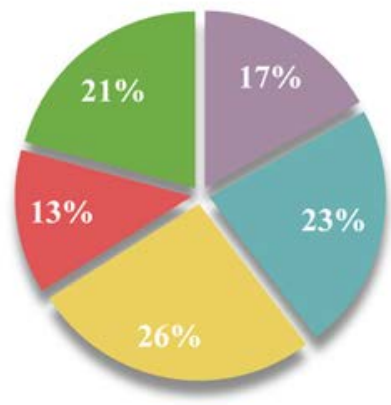

Technical

- Political

social

Economic

Environmental

Figure 3: Weighed percentage share of classified challenges and opportunities.

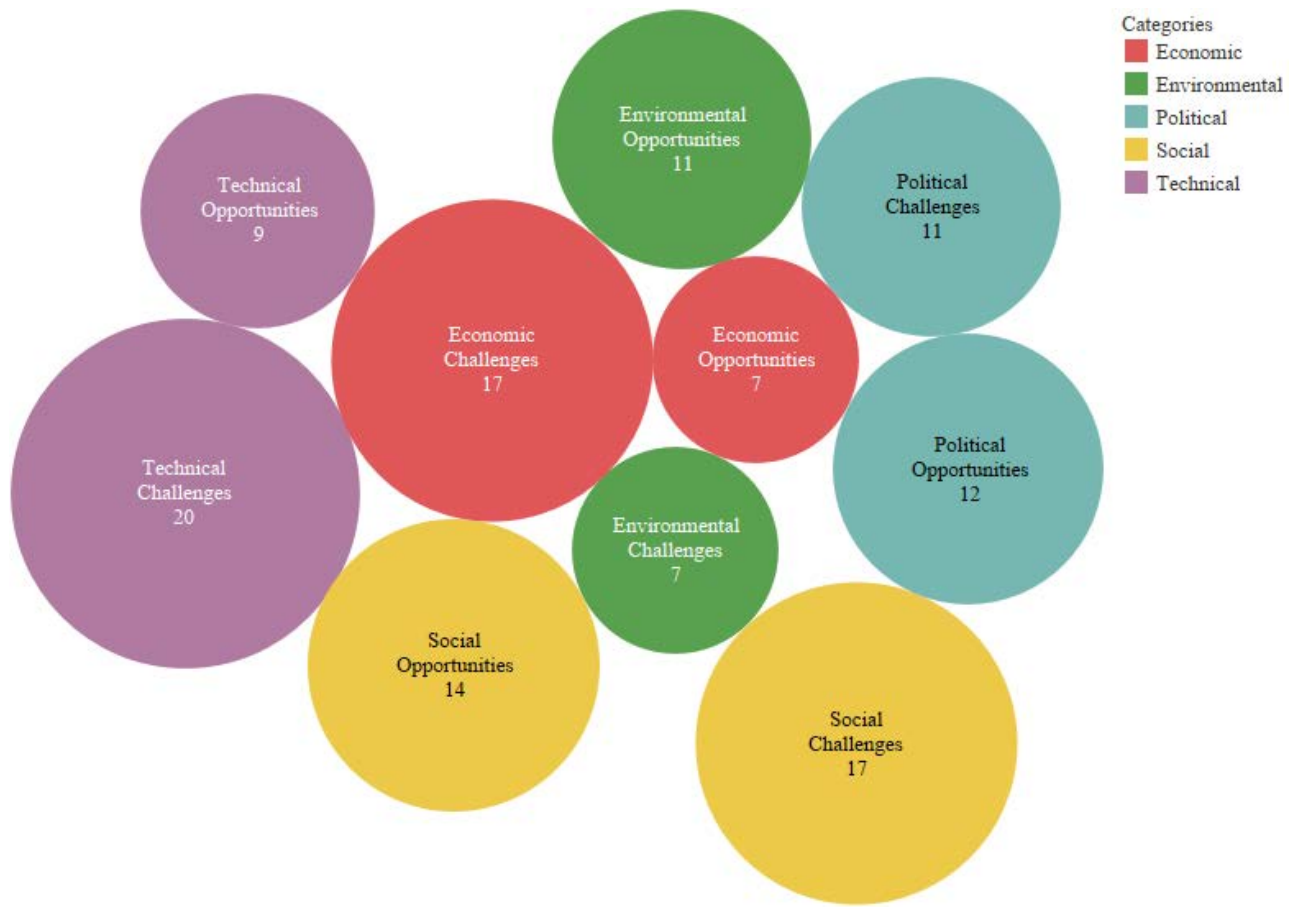

Figure 4: Stacked graphical visualization of identified categories.

and there is hope that Rwanda will gain technical expertise to carry out various activities such as transport master planning and implementation in the next 20 years. Therefore, there is a possibility that the situation will improve in the future. Abundant local labour will present social and technical opportunities. 
On the list of most pressing challenges, social and economic aspects have been found in an equal measure. They all have a score of 17 points which presents about a quarter of all challenges. Limited funds for infrastructure project implementation, and the fact that the government lacks a land bank, are among key challenges. On the side, the unwillingness of residents to relocate, failure to consider actual living standards of urban residents during planning and the rise of car ownership are among top social challenges. Rwanda has an overall non-industrialized economy and a dense population [24]. While there are enormous equal social opportunities, like the dependency on public transport in Kigali, there are quite few economic opportunities that shall facilitate the implementation of the Master plan. All hopes are set upon the expected economic growth. This reiterates the need for Rwanda to seek material funding of transport projects, by both improving the domestic market, using advanced non-expensive technologies in transport projects and prioritizing affordable projects.

A further analsis shows that there is an equal measure of political challenges and opportunities. There are also less environmental challenges in comparison to presented opportunities. The policies of the country are impressively progressive and sustainable [3]. For instance, the government takes a high stand against the use environmentally polluting products in all measures, including construction. They also have put limits of how much cars can evaporate in the atmosphere [25]. Old cars tend to get difficulty finding technical clearance to move inside the city. There is an encouragement of social sport, car-free days and other quite impressive policies. Political and environmental challenges tend to rotate around lack of adequate and inclusive parking spaces. These include moto-taxi for instance. Kigali has a hilly topography, which really is a multi-challenging aspect of transportation [14]. This limits the usage of non-motorized transport, such as the use of bicycles and walking. This also puts a limitation of the implementation of high speed rail networks, which could really improve residents' traffic experience.

\subsection{Limitations}

This paper presents a qualitative review of the Kigali TMP, where the identification of opportunities and challenges has been the key objective. The researchers admit that there are more than what they identified. Therefore, contrasts and comparisons made, looking at various highlighted categories for example, are only limited to identified 37 challenges and opportunities. Arguments that have been made here are not in any way absolute, but are relative. In addition to these, the overlapping aspects of challenges and opportunities, as well as the mutual inclusiveness and exclusiveness, has not been taken care of in the investigation. It is therefore recommended that there should be a further analysis, or research, to solely study the interdependencies of challenges in the transportation master plan, For instance, abundance of local labour is both a social and economic advantage, while finding qualified local urban planners and engineers stands among key challenges. There is therefore a need to clarify quality and quantity iterated issues in an objective manner.

\section{CONCLUSION}

This study had by the main objective to identify various challenges and opportunities presented by the Kigali Transportation Master Plan. Twenty-one key pressing challenges and 16 opportunities have been identified. They have been classified into five categories. Technical and economic challenges are most prominent. The lack of customized and standardized guidelines for traffic engineering and road design specific for Rwanda, and 
limited funding for infrastructure projects are key challenges. The social aspect presents an almost equal share of challenges and opportunities. Some key advantages include the abundance of local labour and the popularity of public transport. The unwillingness to relocate in case of expropriation, and failure to consider daily living standards of citizens poses a major disadvantage, however. On the side, political and environmental aspects of implementing the master plan, presented relatively more opportunities than challenges. Fast and forward, the Government has set high standards of green transport policies that are interwoven by other policy aspects in urban planning. The topographic landscape of the City of Kigali presents a major multi-aspectual disadvantage, however. Both editions of the master plan, 2013 and 2018; coupled with the 2012 Strategic Transport Master Plan have been reviewed. Futureproofing has driven the comparative analysis, considering major transitions that are taking place globally, including climate change and sustainable transportation. Areas of further research have been highlighted. Since all claims and analysis are qualitative, it is admitted that there could be more challenges or opportunities, in addition to what has been identified in this paper. Arguments that have been made here are relative. It is recommended to conduct a further research on the overlapping aspects and mutual exclusiveness of challenges and opportunities in the transportation master plan.

\section{REFERENCES}

[1] National Institute of Statistics of Rwanda, Statistical Yearbook of 2018, NISR: Kigali-Rwanda, 2018.

[2] Baffoe, G., Malonza, J., Manirakiza, V. \& Mugabe, L., Understanding the concept of neighbourhood in Kigali city, Rwanda, Sustainability, MDPI, 12, p. 1555, 2020. www.mdpi.com/journal/sustainability.

[3] Japan International Cooperation Agency, JICA, Data Collection Survey on Development of Urban Transport System in Kigali City, Nippon Koei Ltd., Tokyo, 2019.

[4] The City of Kigali, CoK, Analysis and Vision, Kigali Master Plan 2050, Kigali: The Republic of Rwanda, 2020.

[5] Anandan, H.D.K.K., Detailed Master Plan Report for Nyarugenge District, KigaliRwanda, 2010.

[6] The City of Kigali, Kigali City Transportation Master Plan Report, Kigali: The Republic of Rwanda, 2013.

[7] Sun, J., Li, Z., Lei, J., Teng, D. \& Li S., Study on the relationship between land transport and economic growth in Xinjiang, Sustainability, 10, p. 135, 2018. www.mdpi.com/journal/sustainability.

[8] Debald, M., Road safety assessments, a tool for reducing crashes, and injuries on county roads. A Dutchess County Planning Federation, eNewsletter, pp. 1-2, 2015.

[9] AfDB, Rwanda Transport Sector Review and Action Plan, 2013.

[10] Gerardo, F. \& Bryce, J., Sustainable Pavement Management, 2014.

[11] Pankaj, S., Majithiya, P.D.P. \& Savaliya, K.P., Using road safety audit for urban streets to assess road infrastructure. SSRG International Journal of Civil Engineering (SSRG-IJCE), 3, pp. 269-273, 2016.

[12] Tashobya, A., Construction sector on the spot over environmentally incompliant structures. The New Times, 13 Feb. 2016.

[13] Ministry of Infrastructure, MININFRA, Strategic Transport, The Republic of Rwanda, Kigali, 2012.

[14] The City of Kigali, Nyarugenge district zoning plan report, Kigali Master Plan. The Republic of Rwanda, Kigali, 2013. 
[15] The City of Kigali, Transport Plan, Kigali Master Plan 2050. The Republic of Rwanda, Kigali, 2020.

[16] Richard, M., Transportation planning challenges and opportunities. in Committee on Transportation Planning Applications, Oklahoma, The University of Oklahoma, p. 50, 2011.

[17] Eisenman, A.A.P., Sustainable streets and highways: Analysis of green roads rating systems, 2013.

[18] National Institute of Statistics of Rwanda, The Statistical Yearbook of 2017, The Republic of Rwanda, Kigali, 2017.

[19] Africa Transport Policy Program, Policies for Sustainable Accessibility and Mobility in Cities of Rwanda. The Republic of Rwanda, Kigali, 2018.

[20] NISR, Statistical Yearbook of 2015, Kigali, Rwanda, 2015.

[21] Niyonsenga, D., Assessing Public Transport Supply for Kigali, The University of Twente: Rwanda, Amsterdam, 2012.

[22] Jeanne, N.M., The impact of Kigali city master plan implementation on the living conditions of urban dwellers: Case of Nyarugenge district in Rwanda. Technische Universität München: Munich, 2019.

[23] Hussin, J.M., Rahman, I.A. \& Memon, A.H., The way forward in sustainable construction: Issues and challenges. 2(1), pp. 15-24, 2013.

[24] Irurah, D.K., Agenda for sustainable construction in Africa. Africa Position Paper, 2010.

[25] REMA, Building a climate resilient infrastructure and energy sector for Rwanda, Sep. 2011. 